\title{
Climate change mitigation strategies in fast-growing countries: The benefits of early action ${ }^{t}$
}

\author{
Valentina Bosetti ${ }^{\text {a,b,c }}$, Carlo Carraro ${ }^{\text {b,c,d,e,f }}$, Massimo Tavoni ${ }^{\text {a,b,c,* }}$ \\ a Princeton Environmental Institute, Princeton University, United States \\ b Fondazione Eni Enrico Mattei, Italy \\ c CMCC, Italy \\ d University of Venice, Italy \\ e CEPR, United Kingdom \\ ${ }^{\mathrm{f}}$ CESifo, Germany
}

\section{A R T I C L E I N F O}

\section{Article history:}

Received 8 April 2009

Received in revised form 11 June 2009

Accepted 12 June 2009

Available online 21 June 2009

\section{JEL classification:}

Q54

Q55

Q43

Keywords:

Energy-economy modeling

Climate policy

Developing countries

\begin{abstract}
A B S T R A C T
This paper builds on the assumption that OECD countries are (or will soon be) taking actions to reduce their greenhouse gas emissions. These actions, however, will not be sufficient to control global warming, unless developing countries also get involved in the cooperative effort to reduce GHG emissions. The paper investigates the best short-term strategies that emerging economies can adopt in reacting to OECD countries' mitigation effort, given the common long-term goal to prevent excessive warming without hampering economic growth. Results indicate that developing countries would incur substantial economic losses by following a myopic strategy that disregards climate in the short-run, and that their optimal investment behaviour is to anticipate the implementation of a climate policy by roughly 10 years. Investing in innovation ahead of time is also found to be advantageous. The degree of policy anticipation is shown to be important in determining the financial transfers of an international carbon market meant to provide incentives for the participation of developing countries. This is especially relevant for China, whose recent and foreseeable trends of investments in innovation are consistent with the adoption of domestic emission reduction obligations in 2030 .
\end{abstract}

(c) 2009 Elsevier B.V. All rights reserved.

\section{Introduction}

With the upcoming Copenhagen conference in December 2009, international negotiations over a post-Kyoto treaty are entering a crucial phase. Notwithstanding the consequences of the current economic downturn, there are still high expectations about the possibility of reaching a comprehensive global agreement consistent with the objective of mitigating the consequences of global warming. To be environmentally effective, a climate agreement will need to provide the foundations for overcoming the asymmetric interests and the free-riding incentives that have thus far prevented meaningful coordination of global climate change control.

The new US administration's change of position has removed a long-standing obstacle, so that, despite the remaining differences, concerted climate mitigation action from the major developed

\footnotetext{
is This paper is part of the research work being carried out by the Sustainable Development Programme of the Fondazione Eni Enrico Mattei, and was written as a contribution for the Energy Modeling Forum 22. Financial support from the TOCSIN project is gratefully acknowledged. The usual disclaimer applies.

* Corresponding author. Princeton Environmental Institute, Princeton University, United States.

E-mail address: massimo.tavoni@feem.it (M. Tavoni).
}

countries now seems more probable than ever before. This is an important step forward, since many developing countries have made it clear that their commitment rests on wealthier and more polluting nations' taking action first.

The current upturn in public expenditure which counteracts the current financial and economic turmoil also indicates that governments are focusing on a somewhat "green" recovery, since a sizeable slice (roughly 15\%) of global fiscal stimulus plans has been allocated to low-carbon measures. The US has devoted 112 billion USD for green stimulus. Interestingly, China has allocated twice as many resources (221 billion USD), though mostly in rail and grid infrastructures (Robins et al., 2009).

Although first steps like these are a necessary condition for effective action against climate change, they are not sufficient and further steps are needed. The principle of common but differentiated responsibilities and respective capabilities emphasizes the different roles that Annex 1 (A1) and non-Annex 1 (NA1) countries will play in an international climate agreement. With no consideration for past responsibilities, average per capita emissions in the developing world are still substantially lower than in OECD countries.

However, given the larger and faster growing populations in NA1 regions, the contribution of emerging economies to total emissions 
is becoming substantial. China, in particular, has doubled its emissions since the signature of the Kyoto protocol in 1997, and is now the largest contributor of energy-related $\mathrm{CO}_{2}$ emissions. Today, an average Chinese citizen's emissions are $1 / 4$ those of an average US one. However, assuming continued economic growth - even if it is slower than in the past - and given China's population size, a large number of Chinese citizens may soon reach developed countries' emission levels. For example, according to Chakravarty et al. (2009), in 2030 China may have roughly 100 and 300 million people emitting today's US $\left(20 \mathrm{tCO}_{2}\right)$ and $\mathrm{EU}\left(10 \mathrm{tCO}_{2}\right)$ per capita averages, respectively.

The spikes in fossil fuel prices in recent years are a consequence of fast-growing countries' increasing contribution to global energy demand. Oil price shocks can harm economic growth prospects for emerging economies with low levels of per capita energy consumption, but with large manufacturing, energy-intensive industries ( $\mathrm{Li}$, 2008). This has led many developing countries to pursue policies aimed at increasing energy efficiency, ${ }^{1}$ and has shown that well designed energy policies have the potential to lead to no-regret investment options.

Focusing on the climate problem, it is now clear that developing countries, especially fast-growing regions such as those in the socalled BRIC (Brazil, Russia, India and China), will have a major impact on future emission dynamics and will play a major role in climate negotiations. Results from the WITCH model baseline (see Bosetti et al., 2009) show that even if the OECD regions committed to zero emissions, the attainment of effective climate stabilization objectives would soon be impossible if the rest of the world, especially the BRIC, regions behaved as in the baseline. Non-OECD countries' baseline emissions would exceed the carbon budget allowed for stabilizing radiative forcing between 3.5 and $3.7 \mathrm{~W} / \mathrm{m}^{2}$ (corresponding to 550 ppm $\mathrm{CO}_{2}$ equivalent), between 2030 and 2040; Baseline emissions of BRICs alone would exceed it between 2035 and 2045.

This highlights the need to engage developing countries especially BRICs and foremost China - in GHG mitigation before 2030. The negotiating position of some developing countries has indeed been changing, but incentives will likely be necessary to induce them to join a climate coalition (Victor, 2008). Brazil could apply credit for reducing emissions from deforestation (REDD), whose priority as a mitigation option has been undisputed since the conference of parties in Bali in 2007. China might take on environmental commitments partly in return for stronger guarantees of access to export markets abroad, thus linking trade and environmental policies (Tian and Whalley, 2008). Additional instruments such as funding for technology adoption and adaptation might also be used as accession deals.

Within this complicated and uncertain policy framework, developing countries will need to make important investment decisions in the next few decades, especially in long-lasting infrastructures that will shape the way energy will be consumed. This paper aims at analyzing the implications of different developing countries' decisions to participate in international climate agreements, with a special focus on investment decisions in fast-growing emerging markets.

Using the energy-economy-climate model WITCH (Bosetti et al., 2006), we assess the role of immediate versus delayed participation of developing regions in an international climate agreement. We quantify the implications of fragmented participation in terms of macro-economic policy costs and we investigate the role of technology innovation, adoption and diffusion in smoothing the transition of developing regions to a low-carbon intensive path. In particular, we look at optimal investment strategies in emerging economies in terms of energy capital and knowledge when different assumptions are

${ }^{1}$ China, for example, has set ambitious targets to decrease its energy intensity, though it has struggled to comply with the $20 \%$ reduction goal for 2010 . The current economic recession may make it easier to attain. made about the foresight of their own eventual commitment. We investigate the recent and projected investment trends in innovation and low-carbon technologies in China and compare them to the ones prescribed by a foresight strategy. Finally, we investigate the role of an international carbon market as a way to provide economic incentives for participation. We show that the role of policy anticipation should be taken into account in negotiating emission allocations and has important implications for the international financial transfers involved.

This work is meant to extend our knowledge about regional incentives to adopt effective mitigation policies. It extends the standard climate stabilization economic analysis (see IPCC 4ar WGIII) by analyzing departures from the first-best case of immediate participation and by looking at the incentives and strategies of developing regions. A few recent papers (Bosetti et al., 2008; Edmonds et al., 2007; Keppo and Rao, 2007) - along with those appearing in this volume (Clarke et al., forthcoming) - analyze the role of delayed participation of developing countries in international agreements.

Inter-temporal flexibility is known to be important for the economic efficiency of climate policies and has been analyzed extensively after Wigley et al. (1996). Models featuring perfect foresight, such as DICE (Nordhaus, 1992), FUND (Tol, 1999), MERGE (Manne and Richels, 2004), and WITCH make it possible to analyze the effects of anticipating future climate impacts or policies on optimal investments. Such forward-looking behaviour might differ from short-sighted political reality and should be interpreted as normative. Nonetheless, within the context of second-best climate policies, the role of foresight has received little attention. Bosetti et al. (2008) find that developing countries' incentives to increase emissions because of international leakage are more than counterbalanced by the anticipation of an eventual climate policy, even when such a policy is uncertain. This paper extends their analysis by focusing on optimal investment strategies in technology and innovation for fastgrowing countries.

The structure of the paper is as follows: Section 2 analyzes the implications of immediate versus delayed participation in an international climate agreement. Section 3 focuses on the investment decisions about technology adoption and innovation, with a special focus on policy anticipation in developing countries. Section 4 discusses the role of an international permit market in providing adequate participation incentives. Section 5 concludes the paper by summarizing our main results.

\section{International climate policies: immediate versus delayed participation}

Our analysis starts by looking at international climate policies consistent with the long-term goal of stabilizing atmospheric concentrations. We use the integrated assessment model WITCH ${ }^{2}$ to investigate the economic and investment implications of climate policy, assuming either immediate or fragmented participation. A model description can be found in the Appendix.

WITCH is a hybrid energy-economy-model designed for the economic analysis of climate change policy. A number of modeling features are worth mentioning here, since they are important for the analysis and results presented in this article. WITCH is a forwardlooking model that optimizes over a discounted stream of future investment and consumption decisions; thus, it features perfect foresight and has the ability to anticipate future shocks and policies and incorporate them in current decisions. It is global, with 12 representative macro-regions that interact in a game-theoretic set up, so that their investment decisions are taken strategically with respect

\footnotetext{
${ }^{2}$ See www.feem-web.it/witch for model description and related papers.
} 


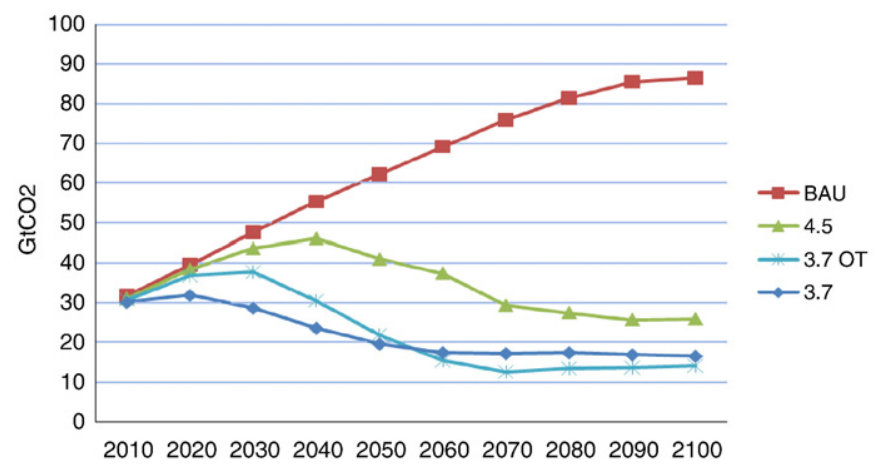

Fig. 1. Energy-related $\mathrm{CO}_{2}$ emissions in the $\mathrm{BAU}$ and the stabilization scenarios for the WITCH model.

to other regions' choices. In addition, it incorporates technological evolution by both diffusion and innovation processes, each characterized by international spillovers. Overall, the model is well suited for investigating the role of various countries' economic incentives to either join or free ride on climate coalitions, as well as for pinning down future inter-temporal effects of climate policies.

The scenario design is coordinated with the Energy Modeling Forum 22 comparison exercise (Clarke et al., forthcomimg). It moves along two main dimensions (the stringency of the overall target and the timing of participation of different world regions), but a third dimension is specifically analyzed in this paper: the level of foresight of regions prior to their commitment. In summary, we focus on the following issues.

- Long-term stabilization targets: in line with the EMF prescription we evaluate four targets, namely the stabilization of greenhouse gases' radiative forcing by 2100 at 2.6, 3.7, 3.7 OT (with overshooting), and $4.5 \mathrm{~W} / \mathrm{m}^{2}{ }^{3}$

- Rate of international participation: two cases are considered in this paper. The first is with IMMEDIATE participation, modeled by a uniform carbon tax starting in 2015. The second one is with MYOPIC delayed participation of developing countries: BRICs join in 2030 and the others in 2050, with a carbon tax starting at the OECD initial values and linearly converging to the OECD one in 20 years.

- Policy anticipation. On the foresight of non-participating countries one possible extreme is to assume myopic behaviour by fixing all the investment variables of late participants to their business-as-usual values obtaining before they join the climate coalition. Scenarios following this assumption, which underlies all the papers in the EMF 22 exercise, imply that developing countries are not allowed to foresee the eventual climate policy, which is then received as a shock. In reality, prior to their engagement countries are likely to partly anticipate the policy and start to choose their technology portfolio accordingly. Hence, we complete our analysis by dropping the myopic assumption and analyzing the effects of policy anticipation on innovation and technology diffusion. We call this delayed scenario FORESIGHT.

While the first two themes are common to the whole EMF 22 comparison exercise, the analysis of policy anticipation and its interplay with innovation and technology investments is very specific to our analysis. It is the focus of the second part of the paper (Section 3).

Fig. 1 reports the carbon emission trajectories produced by WITCH. The graph quantifies the challenge of stabilizing climate at safe levels. The 3.7 scenario, which entails an average end-of-the-century

\footnotetext{
${ }^{3}$ WITCH uses the MAGICC model to determine carbon concentrations and combine radiative forcing from Kyoto gases. The non- $\mathrm{CO}_{2}$ greenhouse gases' baselines and abatement costs figures are taken from EPA, IIASA and EMF21. See the Appendix for details.
}

Table 1

Global macro-economic costs of climate stabilization policies (GWP losses with respect to Business-as-Usual, annualized at 5\% discount rate).

\begin{tabular}{llll}
\hline RF target $\left(\mathrm{W} / \mathrm{m}^{2}\right)$ & Immediate & Myopic & Myopic penalty (USD trillions) \\
\hline 2.6 & Infeasible & Infeasible & - \\
3.7 & $1.26 \%$ & $2.53 \%$ & 25 \\
3.7 OT & $1.11 \%$ & $1.50 \%$ & 8 \\
4.5 & $0.06 \%$ & $0.10 \%$ & 0.2 \\
\hline
\end{tabular}

warming of $2.5^{\circ} \mathrm{C}$, requires that emissions are already significantly reduced in 2020, whereas the 3.7 OT and 4.5 allow for more gradual mitigation. We will show that the choice of target has major implications for the delayed participation scenarios, as expected.

The $2.6 \mathrm{~W} / \mathrm{m}^{2}$ scenario is not shown as it is not feasible within our modeling framework. ${ }^{4}$ It requires assuming the possibility of deploying negative emission technologies that are not considered in the technical and economic assumptions behind the model. Also, since our description of technology innovation requires upfront investment costs in R\&D whose payoff accrues only over the course of a few decades, we find it impossible to comply with the immediate drastic emission reductions required by the low-forcing scenario.

Table 1 reports the macro-economic policy costs of the various scenarios for the immediate and myopic cases. Costs increase nonlinearly with the stringency of the target; the looser 4.5 target has small costs, whereas the 3.7 entails a gross world product (GWP) loss somewhat above $1 \%$, depending on the possibility to momentarily overshoot the long-term radiative objective.

Table 1 also shows the global economic costs of the same policies with countries' fragmented myopic participation. In the 3.7 case, policy costs roughly double, to a $2.5 \%$ GWP loss; equivalently, the penalty amounts to the very significant figure of 25 trillion USD, in net present value. This shows that a serious climate mitigation objective requires a large coordinated effort that involves all major emitters from the start. Otherwise, the global costs of achieving the target rise very significantly, with GDP losses as high as $4 \%$ in 2050.

Allowing for target overshooting has the potential to reduce this penalty; global costs increase to $1.5 \%$, and the delayed accession economic penalty becomes 8 trillion USD. Though still sizeable, overshooting manages to reduce it by two-thirds. Breaching the target would generate higher transient temperatures and increase the risk of missing the target if technology evolution did not develop as planned, but this should be weighed against the significant alleviation of the economic penalty due to delayed participation. Finally, when a relatively loose target such as the $4.5 \mathrm{~W} / \mathrm{m}^{2}$ is endorsed, the increase in policy costs would still be large in relative terms, but not in absolute levels, given the initial low policy costs. In this case, the delayed accession penalty would be on the order of 0.2 trillion USD.

The reason for the high delayed participation markup is that developed regions are confronted with a much higher mitigation effort at least until the middle of the century, given the bullish predictions for emission growth in fast-growing economies such as the BRICs and their long-lasting investments in carbon-polluting infrastructure.

Fig. 2 shows the carbon prices for the 3.7 case. OECD countries need much higher carbon prices to achieve the higher mitigation effort, given the convexity of marginal abatement costs. Carbon prices are significantly above the ones resulting from immediate participation due to the foregone abatement opportunities in the developing world. For example, in 2030 , carbon prices reach $500 \$ / \mathrm{tCO}_{2} \mathrm{eq}$, as opposed to less than $100 \$ / \mathrm{tCO}_{2} \mathrm{eq}$ in the immediate participation case.

\footnotetext{
${ }^{4}$ Specifically, the optimization algorithm can't find a solution that matches the emission constraints implied by the stabilization scenario.
} 


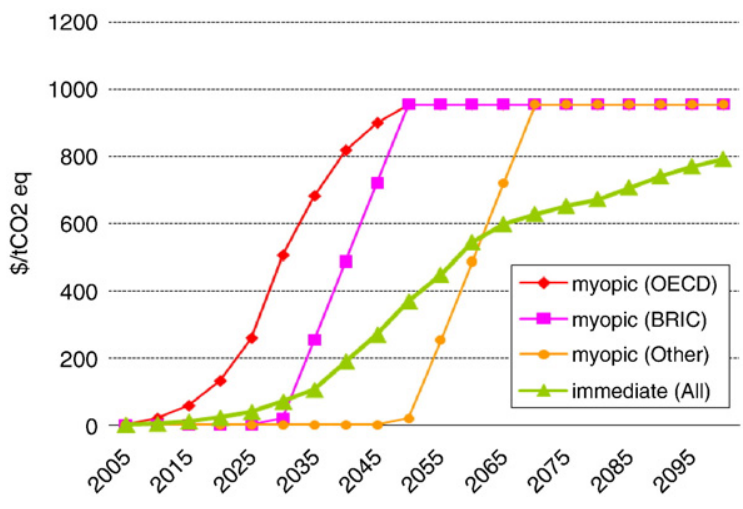

Fig. 2. Price of carbon for the $3.7 \mathrm{~W} / \mathrm{m}^{2}$ scenarios, immediate and myopic cases.

Carbon prices realign very slowly over the century, given that developing regions, by behaving myopically - i.e. by ignoring the upcoming climate commitment - build the same significant amount of long-lasting carbon-intensive capital that they would have accumulated in a climate unconcerned world, and forego the innovation programs. The lock-in fossil investments are such that even in 2100, at the time when all regions cooperate and share the same shadow value of carbon, the markup carbon price of delayed participation is still about $150 \$ / \mathrm{tCO}_{2}$.

These results show that the delayed participation of developing countries in the international effort to curb carbon emissions might cast doubt on the feasibility of serious climate protection objectives, though this would not necessarily be the case for less ambitious (and effective) objectives. We now relax the assumption of myopic behaviour to analyze the benefits of policy anticipation for technology adoption and innovation choices.

\section{Perfect foresight, innovation and delayed action in fast-growing countries}

The detrimental effects of delayed participation, both in terms of policy costs and technology deployment - shown in the previous section - are strictly linked to the dynamics of investments in developing countries and the assumptions concerning policy anticipation. Indeed, a few decades of investments in fast-growing economies without consideration for future climate changes are sufficient to lock in a stock of polluting capital that has long-lasting consequences, and whose early retirement is extremely expensive. On the other hand, developing countries are reluctant to modify their short-term investment strategy, given their pressing development needs. However, they also know that they might well join a global cooperative effort to reduce GHG emissions sometime in the future, given the common goal to prevent excessive warming without hampering economic growth and given the present rapid growth of their GHG emissions.

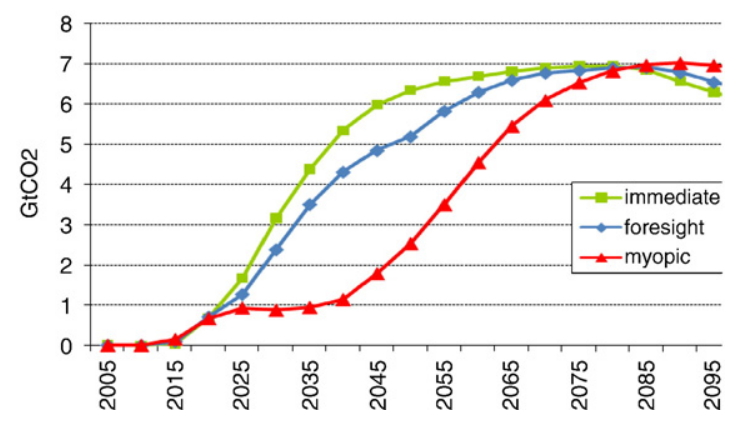

Fig. 3. Carbon captured and stored geologically $\left(3.7 \mathrm{~W} / \mathrm{m}^{2}\right.$ scenario).

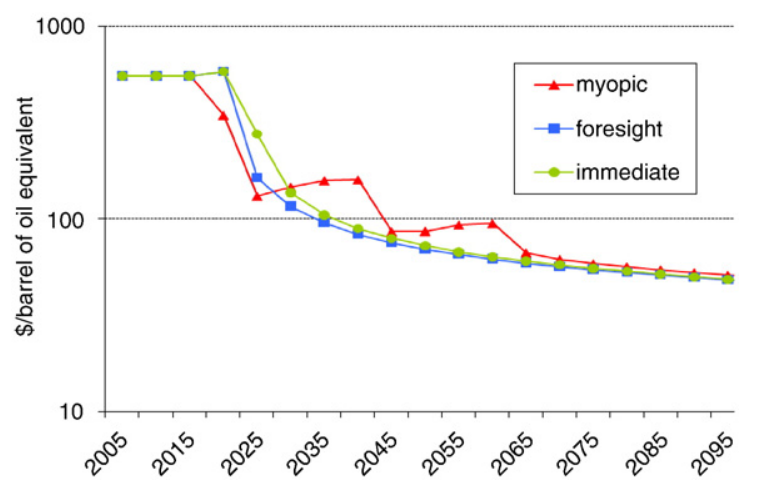

Fig. 4. Cost of a breakthrough technology, world average ( $3.7 \mathrm{~W} / \mathrm{m}^{2}$ scenario).

One might therefore wonder to what extent policies that materialize in the future are built into today's investment decisions. Public and private investment decisions will likely incorporate some expectations about future climate policy when capital with long-term turnover is at stake, as is the case for power generation plants or transport infrastructure. National policies might also be brought in earlier. At the same time, policy implementation in some but not all parts of the world might spur leakage effects, such as leakage in developing regions due to lower international prices of fossil fuels.

Thus, the assumption - embedded in the previous section's results that non-signatory countries myopically follow their business-as-usual investment paths when OECD countries decide to mitigate their own GHG emissions may be erroneous. In this section, we investigate the optimal investment strategies of fast-growing countries; that is, we drop the assumption of myopic behaviour by relieving their investment and consumption choices from the BAU constraint and allowing for foresight of future policies. We restrict our attention to the most relevant case of a long-term radiative forcing target of $3.7 \mathrm{~W} / \mathrm{m}^{2}$.

Prior to non-participating countries' commitment to a climate target, their behaviour is affected by three different factors:

- Fossil fuel prices: the stringent climate target developed regions are already committed to have an obvious effect on their consumption of fossil fuels, which is reflected in their prices. Because of this leakage effect, countries not yet involved in the climate agreement have access to cheaper resources and have the incentive to increase their emissions compared with the case in which there is no agreement.

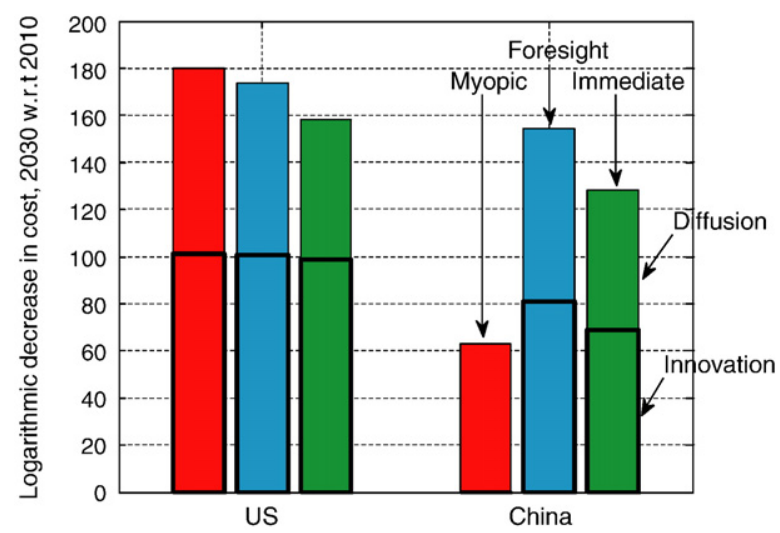

Fig. 5. Decomposition of technological change for the breakthrough technology for the US and China ( $3.7 \mathrm{~W} / \mathrm{m}^{2}$ scenario). The bars show the (log) decrease of the cost of the breakthorugh tehcnology in 2030 w.r.t. 2010 for the myopic, foresight and immediate cases. The lower countoured part of each bar shows the contribution of innovation and the upper the one by diffusion. 

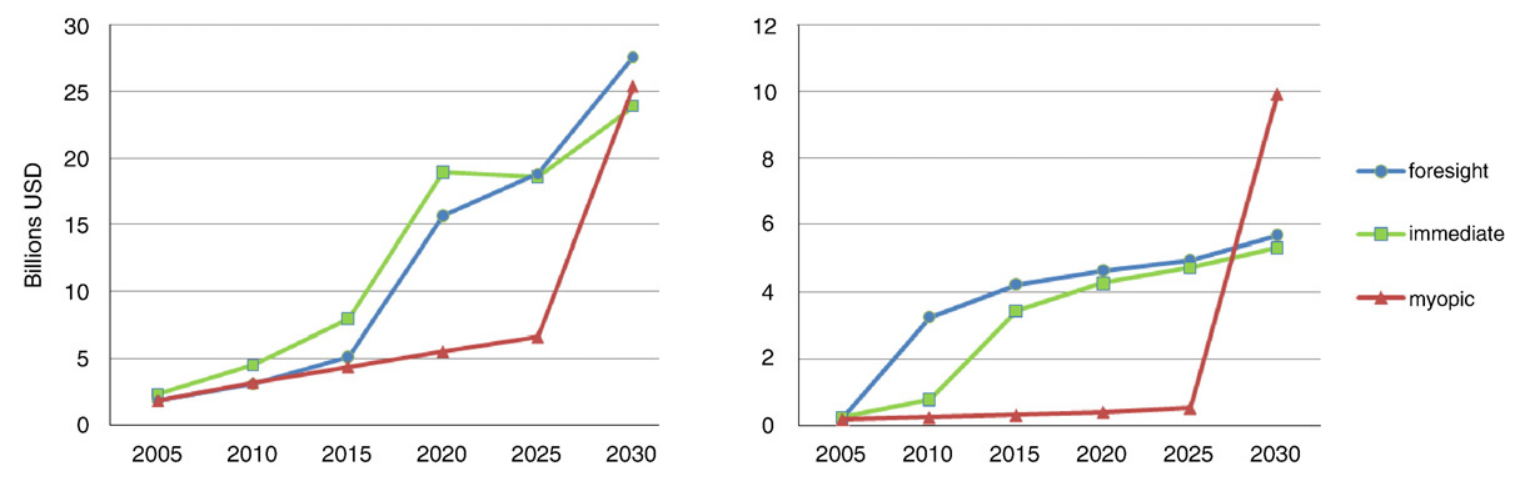

Fig. 6. Investments in nuclear power (left panel) and energy R\&D (right panel) in China ( $3.7 \mathrm{~W} / \mathrm{m}^{2}$ scenario).

- Technological spillovers: OECD countries' commitment to a climate policy fosters technical change in low-carbon technologies and energy efficiency, thus also making them economically attractive in developing countries via international spillovers of knowledge and experience.

- Policy anticipation: when perfect foresight is accounted for, countries 'price-in' the future carbon price in their investment choices and, given the low turnover of energy capital and the lag time in the innovation processes, adjust their portfolio of investments accordingly.

\subsection{Deployment and innovation of low-carbon technologies}

We start by investigating the implications of developing countries' delayed participation and policy anticipation for the deployment of carbon abatement technologies. Developing countries are believed to host a substantial number of cheap mitigation options, which arise from high energy intensity and capital replacement as a result of rapidly expanding economies.

Carbon capture and storage (CCS) is considered to be an important low-carbon technology, because it would allow the world to continue to use affordable fossil fuels and at the same time reduce carbon emissions. Therefore, it is expected to play an important role, especially in countries that heavily rely on coal for generating electricity, such as China and India. Fig. 3 shows that developing countries' degree of policy anticipation has important repercussions for the global deployment of CCS. A myopic strategy would reduce the diffusion of CCS significantly, imposing a 20-year delay that would be made up only at the very end of the century. By contrast, if policy is anticipated, CCS develops at rates similar to the first-best scenario.

Technological innovation is also affected by the extent and anticipation of international participation in a climate agreement. Fig. 4 shows the cost of an advanced, representative carbon-free technology in the non-electricity sector that is initially uncompetitive

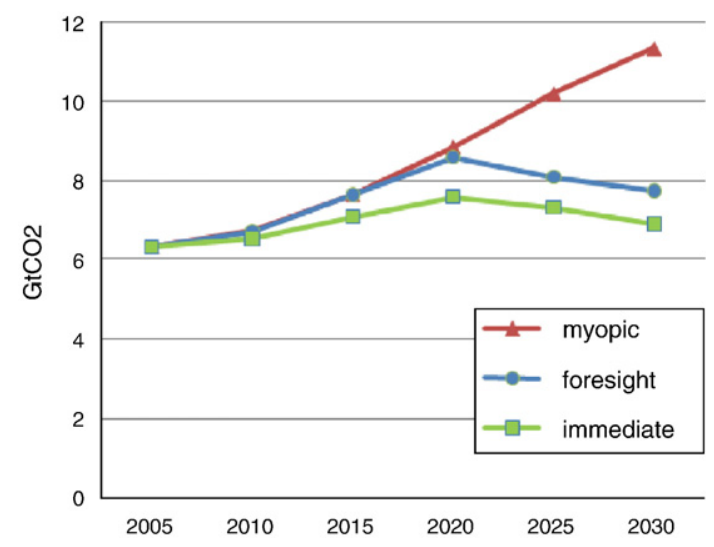

Fig. 7. Energy-related carbon emissions in China $\left(3.7 \mathrm{~W} / \mathrm{m}^{2}\right.$ scenario). (at roughly $500 \$ /$ barrel of oil equivalent), but whose unit cost can be decreased by both diffusion via learning by doing and by innovation via dedicated R\&D investments through a two-factor learning curve (see Appendix for modeling details). The graph shows that at first the price of this new technology decreases faster in the myopic case; this is due to the fact that in this case developed regions, facing a more stringent early mitigation goal, invest more in the commercialization of this technology. Given that they are initially the repository for most of the world's energy knowledge capital, a shift of the mitigation effort from developing to developed countries fosters higher initial technological change.

Soon after, however, the cost of the technology in the two cases switches, becoming and remaining cheaper in the immediate participation scheme. The cost in the foresight case closely follows the cost in the immediate one.

This behaviour is explained by the various forces that drive technological evolution in the model. The breakthrough technology can be made competitive by both deployment - modeled as cumulative installed capacity - and innovation - modeled through a dedicated knowledge stock. Both sources are subject to international spillovers: the learning by doing part is assumed to spill over freely, as it is determined by the global deployment of the technology. On the other hand, the appropriation of the 'learning by researching' component requires local innovation investments to build up absorption capacity and is lost under a myopic climate unconcerned strategy.

Fig. 5 disentangles these two components for two representative regions, the US and China. ${ }^{5}$ The picture shows that the decrease in the breakthrough technology cost in the US would be marginally affected by the rate of participation and foresight of developing countries. The innovation component is roughly equal across the three scenarios, given that the OECD regions host most of the energy knowledge capital and would hardly benefit from spillovers from developing countries. The diffusion part is actually higher in the myopic scenario, since in this case OECD regions face a more stringent mitigation target and deploy more of the technology, as noted above.

Quite a different picture emerges for China. In the myopic case, the innovation part is lost because no $R \& D$ investment in the breakthrough technology is envisaged in this baseline-like scenario. This prevents China from being able to lower the cost of the technology through domestic learning by researching and through absorption of developed countries' knowledge via international spillovers. There would still be a diffusion component given the world spillovers, but it would fall short of compensating for the lost innovation part. In the end, by following a myopic strategy China would lose more than half of the gains from the competitiveness of this important low-carbon mitigation option.

\footnotetext{
${ }^{5}$ Given the Cobb-Douglas type production function of the two-factor learning curve specification, the logarithmic change of the cost of the technology is the average of the diffusion and innovation parts, weighted by their learning rates.
} 
On the other hand, a foresighted strategy that anticipates the forthcoming policy would allow China to fully capture the potential technological change, even slightly more so than in the immediate participation case since, even with the foresight assumption, the delayed participation of developing countries outside the BRICs burdens China with a larger share of mitigation effort between 2030 and 2050.

These results point to geographical asymmetry in the impacts of delayed participation and foresight on technological change. As far as innovation is concerned, OECD countries would be only slightly affected by the reluctance of developing regions to commit to carbonfree investments. On the other hand, if emerging economies follow a myopic scenario they may forego opportunities to innovate and profit from the OECD research effort.

\subsection{Optimal investment strategies in emerging economies: the case of China}

The previous section has shown that the degree of policy anticipation can have important effects on the way low-carbon technologies are deployed and developed. The consequences are global but have been shown to be particularly important for emerging economies. In this section we focus on the optimal energy investment strategies that fast-growing countries should undertake under different assumptions of foresight. We ask ourselves when and to what extent a major emerging economy like China should deviate from a baseline trajectory and endorse a climate-friendly investment path.

Fig. 6 shows investments in China in nuclear power generation and public energy R\&D. Investments in nuclear power plants in the foresight case depart from the baseline myopic case as early as 2015, soon closing the gap with the immediate participation case. In 2020, China invests 3 times as much in nuclear power plants as in the baseline, from 5 to 15 billion USD. By 2030, the foresight and immediate cases entail roughly $70 \mathrm{GW}$ of nuclear power capacity, as opposed to $30 \mathrm{GW}$ in the myopic case. China has recently embarked upon what seems to be an ambitious nuclear power generation plan, with a 2020 declared target of $40 \mathrm{GW}$, and officials are now claiming that this objective may be exceeded by $50 \%$, reaching $60 \mathrm{GW}$ by $2020 .{ }^{6}$

The surge in public energy R\&D investments, given the long commercialization lag times and the smaller investment amounts, starts even earlier, heading off baseline 15 years before. Interestingly, $R \& D$ investments are higher in the foresight case than in the immediate participation one, reaching 4 billion USD a year. The reason for this is that, in the delayed foresight case, developing countries outside BRICs do not join the coalition until 2050. Thus, BRICs need to undertake more mitigation and invest more heavily and earlier in R\&D to build up a sufficient knowledge stock to reduce future mitigation stocks.

In recent years, China has significantly increased its total R\&D spending ${ }^{7}$; it currently stands at $1.5 \%$ of GDP, or roughly 40 billion USD, a level similar to that of many Western countries, but still behind the world leading R\&D investors such as the US and Japan. Nevertheless, China is moving to become a global technological and scientific powerhouse. It has a stock of human resources for science and technology second only to the US and has set a global R\&D spending target of $2.5 \%$ of GDP by 2020 . Even assuming a conservative estimate of $2 \%$ of energy R\&D over total R\&D, this would imply a figure of roughly 4 billion USD, in line with the foresight scenario shown above. Overall, one can say that observed and projected R\&D investments in green energy are consistent with the adoption of domestic emission reduction obligations by China in 2030 .

\footnotetext{
${ }^{6}$ http://www.reuters.com/article/rbssConsumerGoodsAndRetailNews/idUSL 0868760220080308.

7 We thank Dabo Guan for providing us with data and details.
}

Table 2

Global and regional macro-economic costs of climate stabilization policies, $3.7 \mathrm{~W} / \mathrm{m}^{2}$ (GWP losses with respect to Business-as-Usual, annualized at 5\% discount rate).

\begin{tabular}{lllll}
\hline Region & Immediate (\%) & Myopic (\%) & Foresight (\%) & Efficiency gains of foresight (\%) \\
\hline World & 1.26 & 2.53 & 1.57 & 38 \\
OECD & 0.7 & 2.55 & 1.33 & 48 \\
BRICs & 2.1 & 3.14 & 2.45 & 22 \\
Other & 2.2 & 0.46 & 0.36 & 22 \\
\hline
\end{tabular}

The investment patterns indicate that policy anticipation would prompt early action in a major emerging economy such as China. Such a deviation from baseline would materialize in earlier mitigation of $\mathrm{CO}_{2}$ emissions. Fig. 7 reports fossil-related carbon emissions in China for the various cases. The picture shows that carbon policy is anticipated by roughly 10 years and that carbon emissions are mitigated with respect to the baseline case when farsightedness is accounted for. The abatement does not occur till 2020, but is quite substantial afterwards, so that by the time China joins the climate coalition in 2030, emissions are much closer to the case of immediate participation than to the baseline.

\subsection{The economic benefits of early action}

In the previous section we showed that the optimal investment strategy in developing countries is to anticipate the climate policy by roughly 10 years ( 15 years for innovation). We now quantify the economic implications of policy anticipation for both developing and developed countries.

Table 2 compares the climate policy costs in the perfect foresight case and in the other cases as well. Global costs with delayed accessions but policy foresight are $1.57 \%$ of GWP, higher than the $1.2 \%$ of immediate participation, but substantially lower than the $2.53 \%$ of the myopic case. Equivalently, foresight decreases the global economic penalty of delayed participation from 25 to 6 trillion USD, bringing it below the case of radiative forcing overshooting analyzed in Section 2.

Table 2 also reports regional policy costs. Several things emerge. The first is that, in the delayed myopic scenario, policy costs increase very significantly for OECD countries, but also for BRICs. This is because capital building in carbon-intensive technologies and the delayed accession of other developing countries - among which are big emitters such as South Africa and energy exporting regions require a radically higher carbon price when they start to participate. As shown in Fig. 2, given the assumed harmonization of carbon prices in a 20-year time span after having joined the climate coalition, BRICs regions could expect a carbon price of zero to 2030 in the delayed case, but a substantially higher one afterwards. Hence, they are worse off compared with the immediate participation case. The other countries also eventually face a higher carbon price, but this occurs far into the century so that the net present value policy costs are lower in the delayed myopic case.

Second, policy anticipation via perfect foresight benefits all regions, but especially $\mathrm{OECD}$ countries. Given that large emerging economies reduce emissions similarly to the immediate participation case as shown above, the OECD countries' extra mitigation job is reduced substantially, and so are their costs. BRICs' smoothing of abatement to earlier periods relieves them of the eventually higher carbon prices, and accordingly eases the economic burden. Other countries benefit by both theirs and BRICs optimal investment choices, further reducing their compliance costs.

Finally, Table 2 shows that some developing countries could be badly hurt by climate policy. Carbon price harmonization in the immediate participation case imposes higher costs on non-OECD regions, given their higher energy expenditure as a share of GDP and their reliance on carbon-intensive fuels (such as coal for big regions 
Table 3

Financial transfers ( + outflow, - inflow) in an international carbon market (billions of USD), $3.7 \mathrm{~W} / \mathrm{m}^{2}$ scenario, for two allocation schemes.

\begin{tabular}{lccccc}
\hline $\begin{array}{l}\text { Allocation } \\
\text { scheme }\end{array}$ & 2020 & & & 2030 & \\
\cline { 2 - 3 } & Myopic (BAU) & Foresight & & Myopic (BAU) & Foresight \\
\hline OECD & 94.2 & 23.6 & & 197.2 & 147.8 \\
BRICs & -75.6 & -17.1 & & -152.8 & -65.6 \\
Other & -18.6 & -6.5 & & -44.4 & -82.2 \\
\hline
\end{tabular}

like China and $\left.\operatorname{India}^{8}\right)$. In the delayed scenarios, the assumption that carbon prices converge in 20 years is such that BRICs regions remain the ones with higher climate policy costs, whereas the other developing regions' costs drop visibly. Nonetheless, participation incentives might be provided to alleviate part of this burden. The next section tackles this issue, by looking at the role of an international carbon market.

\section{The role of an international carbon market}

One of the instruments with the potential to increase the participation rate in global climate agreements is an international carbon market. Such a scheme would increase policy efficiency by equalizing marginal abatement costs, and could help developing countries finance energy and carbon efficiency measures. Assuming a perfect market with no transaction costs, the marginal price of carbon would be unrelated to the initial allocation of carbon permits, but regional gains or losses would be affected. Ideally, the allocation scheme would provide sufficient participation incentives to developing countries, without requiring excessively large transfers from developed regions.

One possibility is to allow developing countries to trade emission reductions below their baseline, as a way to provide economic support for the transition to a low-carbon society. However, the choice of baseline is not an obvious one, since developing countries, especially the fast-growing ones with large investment possibilities, might incorporate energy- and carbon efficiency-enhancing measures into their baseline anyway, as a way to prepare for a low-carbon and energy-independent economy.

We tackle this issue by carrying forward the scenarios analysis presented in the previous sections. We simulate a perfect international carbon market starting in 2015 and consider two cases. In the first one, non-signatory countries are allocated an initial endowment equal to their emissions in the myopic (which equals the baseline) scenario. In the second one, the initial endowment corresponds to emissions in the foresight case. For example, before joining in 2030, China would get an allocation equal to the ones shown in Fig. 7 for the two delayed scenarios.

The myopic allocation thus rewards any emission reduction with respect to a "never climate concerned baseline"; by contrast, the foresight allocation assumes that emerging economies would incorporate future (post-2030) climate policy in their actions anyway, and raises the bar by allowing carbon trading below the lower emission trajectory of a "future climate concerned baseline". Given the differences in emission pathways across these two cases (reported in previous sections), we expect different carbon trading across the two schemes.

\footnotetext{
${ }^{8}$ One might ask whether this is related to the modeling choice of market exchange rates versus PPP, which leads to an initially higher energy intensity of the economy. Although developing countries are probably more efficient than predicted by MER, especially on the consumption side, the MER approach reflects the fact that emerging economies such as China have substantially higher fractions of their emission from industry than from households compared with developed regions. Many of the manufactured products are also traded internationally. Over time, MER's higher energy intensity improvements over PPP ensure convergence.
}

Indeed, in the myopic allocation the quantity of carbon traded is roughly twice that in the perfect foresight one; the average between 2015 and 2030 is $5.1 \mathrm{GtCO}_{2} \mathrm{eq} /$ year in the first case, and $2.56 \mathrm{GtCO}_{2} \mathrm{eq} /$ year in the second. This figure should be compared to the total global abatement effort that the world undertakes, which averages $11 \mathrm{GtCO}_{2-}$ eq/year during the same period. That is, in the myopic case, $1 / 2$ of the total abatement is achieved via international carbon transfers, whereas in the perfect foresight case that ratio is about $1 / 3$.

The regional distribution of carbon trading also changes; in the myopic case, $80 \%$ of OECD carbon purchases come from BRICs and $20 \%$ from other developing countries. In the foresight case, the shares are $60 \%$ and $40 \%$. The reason is that BRICs' emission reduction due to policy anticipation in early periods is higher than other developing countries', since the former are expected to take on climate policy obligations earlier than the latter.

The resulting financial transfers associated with these two possible implementations of a carbon trading market are reported in Table 3. In 2020, OECD countries transfer up to 94 billion USD to developing countries in the myopic case, instead of 23 billion in the perfect foresight case. These figures increase to almost 200 and 150 billion respectively in 2030 , due to more trading and higher carbon prices.

These numbers show that carbon trading can entail quite significant financial transfers, especially in the myopic case, where they reach $0.4 \%$ of OECD GDP in 2030. Our results also show that transfers can be reduced by adopting an allocation scheme in which developing countries' anticipation of future climate policy measures is taken into account.

\section{Conclusions}

This paper has looked at different participation schemes in a future international climate agreement aimed at long-term climate stabilization. Using a numerical energy-economy-climate model we have shown that delayed participation of fast-growing countries in a global climate treaty increases the cost of climate policy. The magnitude of the penalty with respect to the ideal case of immediate participation can be large, but depends on the stringency of the target and on the possibility to temporarily breach the long-term climate objective. Technology adoption and diffusion could also be jeopardized.

Starting from the assumption that OECD countries are (or will soon be) committed to reducing their own GHG emissions, we have analyzed the best short-term investment strategies for developing countries, especially for fast-growing countries such as BRIC. Our results indicate that the optimal investment behaviour for emerging economies is to anticipate climate policies by roughly 10 years, and incorporate future carbon prices into short-term energy investment decisions (both in the deployment of low-carbon technologies and for innovation via R\&D). A specific investigation of the actual and projected trends in green innovation and low-carbon technologies in China has revealed an investment pattern compatible with the adoption of an emission mitigation policy by 2030 .

Policy foresight appears to have the potential to significantly ease the mark up of delayed participation. The paper also evaluated the role of an international carbon market, and we suggest that allocation schemes equal to or below baseline can provide developing countries with participation incentives. In particular, recognizing emission reductions below fast-growing economies' optimal policy foresight strategy could encourage their accession without implying excessively large financial transfers from developed countries.

\section{Appendix A. Supplementary data}

Supplementary data associated with this article can be found in the online version at doi: 10.1016/j.eneco.2009.06.011. 


\section{References}

Bosetti, V., Carraro, C., Galeotti, M., Massetti, E., Tavoni, M., 2006. WITCH: a world induced technical change hybrid model. The Energy Journal. Special Issue on Hybrid Modeling of Energy-Environment Policies: Reconciling Bottom-up and Top-down $13-38$.

Bosetti, V., Carraro, C., Tavoni, M., 2008. Delayed participation of developing countries to climate agreements: should action in the EU and US be postponed? Fondazione Eni Enrico Mattei, Working Paper N.70-2008.

Bosetti, V., Carraro, C., Massetti, E., Sgobbi, A., Tavoni, M., 2009. Optimal energy investment and R\&D strategies to stabilise greenhouse gas atmospheric concentrations. Resource and Energy Economics 31-2, 123-137.

Clarke, L., Edmonds, J., Krey, V., Richels, R., Rose, S., Tavoni, M., forthcoming. International climate policy architectures: overview of the EMF 22 International Scenarios, Energy Economics.

Chakravarty, S., Chikkatur, A., de Coonik, H., Pacala, S., Socolow, R., Tavoni, M., 2009 Sharing global $\mathrm{CO}_{2}$ emission reductions among one billion high emitters. Proceedings of National Academy of Science. 106, 11884-11888.

Robins, N, Clover, R., Singh, C., 2009. A climate for recovery: the colour of stimulus goes green. HSBC Global Research 25 February 2009 issue, 1-45.
Edmonds, J., Clarke, L., Lurz, J., Wise, M., 2007. Stabilizing $\mathrm{CO}_{2}$ concentrations with incomplete international cooperation. October 2007, PNNL working paper.

Keppo, I., Rao, S., 2007. International climate regimes: effects of delayed participation. Technological Forecasting and Social Change 74 (7), 962-979.

Li, M., 2008. Peak energy and the limits to China's economic growth: prospect of energy supply and economic growth from now to 2050. Political Economy Research Group Working Paper 189, Dec 2008.

Manne, A., Richels, R., 2004. MERGE: an integrated assessment model for global climate change. Stanford University.

Nordhaus, WilliamD., 1992. The "DICE" model: background and structure of a dynamic integrated climate-economy model of the economics of global warming. Discussion Paper, Cowles Foundation for Research in Economics at Yale University.

Tian, H., Whalley, J., 2008. China's participation in global environmental negotiations. NBER Working Paper No. 14460, Oct 2008.

Tol, R.S.J., 1999. Spatial and temporal efficiency in climate change: applications of FUND. Environmental and Resource Economics 14 (1), 33-49.

Victor, D.G., 2008. Climate accession deals: new strategies for taming growth of greenhouse gases in developing countries. Discussion Paper 08-18, Cambridge, Mass.: Harvard Project on International Climate Agreements, Dec 2008.

Wigley, T., Richels, R., Edmonds, J.A., 1996. Economic and environmental choices in the stabilization of atmospheric $\mathrm{CO}_{2}$ concentrations. Nature 379 (6562), 240-243. 